\title{
BMJ Open Characteristics and factors associated with post-exposure prophylaxis (PEP) treatment of dog and cat bites among left-behind children: a cross-sectional study in two cities of China
}

\author{
Shuzhen Yan, ${ }^{1}$ Ying Chen, ${ }^{1,2}$ Wanbao Ye, ${ }^{1}$ Fuxiang Chen, ${ }^{1}$ Liping $\mathrm{Li}^{1}$
}

To cite: Yan S, Chen Y, Ye W, et al. Characteristics and factors associated with postexposure prophylaxis (PEP) treatment of dog and cat bites among left-behind children: a cross-sectional study in two cities of China. BMJ Open 2019;9:e024764. doi:10.1136/ bmjopen-2018-024764

- Prepublication history for this paper is available online. To view these files, please visit the journal online (http://dx.doi org/10.1136/bmjopen-2018024764).

Received 15 June 2018 Revised 31 March 2019 Accepted 1 April 2019

\section{Check for updates}

(c) Author(s) (or their employer(s)) 2019. Re-use permitted under CC BY-NC. No commercial re-use. See rights and permissions. Published by BMJ.

${ }^{1}$ Injury Prevention Research Center, Shantou University Medical College, Shantou, China ${ }^{2}$ School of Public Heath, Sun Yat-sen University, Guangzhou, Guangdong, China

Correspondence to Professor Liping Li; Ipli@stu.edu.cn

\section{ABSTRACT}

Objective Animal injury is a significant cause of morbidity and mortality worldwide. Dog bites account for tens of millions of injuries annually and the highest risk is among children. However, children may not receive postexposure prophylaxis (PEP) treatment timely and appropriately after rabies exposure. This study aimed to investigate the characteristics and factors associated with PEP treatment of dog and cat bites among left-behind children.

Design A cross-sectional study using questionnaire was conducted in primary and high schools.

Setting Shenzhen and Shantou cities, Guangdong Province, China.

Participants A total of 9380 participants were included and 2236 of them were with a history of dog and cat bites. Results 1188 (53.1\%) boys and 1048 (46.9\%) girls suffered from animal bites. Bitten in holidays was less likely to receive PEP treatment (OR $0.512,95 \% \mathrm{Cl} 0.377$ to $0.695)$ than those bitten in school days. Bitten while being with family (OR 1.418, 95\% Cl 1.040 to 1.934) and bitten at roadside (OR $1.842,95 \% \mathrm{Cl} 1.297$ to 2.171$)$, bitten by unvaccinated animals (OR 1.745, 95\% $\mathrm{Cl} 1.246$ to 2.443 ) tended to receive PEP treatment. Compared with unbroken skin, bleeding (OR 1.789, 95\% $\mathrm{Cl} 1.165$ to 2.745$)$ and laceration (OR $3.834,95 \% \mathrm{Cl} 2.310$ to 6.366 ) were showed as treatment prompting factors.

Conclusions Bitten in holidays was found as a risk factor of receiving PEP treatment of animal bites. Certain measures should be taken to raise left-behind children's awareness of receiving PEP treatment timely and appropriately after dog and cat bites.

\section{INTRODUCTION}

Animal bites are common worldwide, which remains a serious public health problem. In the USA, 200 per 100000 persons are estimated to suffer from animal bites each year. ${ }^{1}$ In Germany, the incidence of bites is 30000-50000 injuries per year. ${ }^{2}$ Rabies is preventable yet it is responsible for roughly 59000 deaths per year. ${ }^{3}$ A study estimates that globally canine rabies causes $\sim 59000$ human deaths, over 3.7 million disability-adjusted
Strengths and limitations of this study

- Our study focused on left-behind children which was a vulnerable group.

- Our study was the first of its type to investigate the characteristics and factors associated with post-exposure prophylaxis treatment of dog and cat bites among left-behind children in Shenzhen and Shantou cities, China.

- Response bias may be present, and limit generalise to represent the overall population of China.

life years and US\$ 8.6 billion economic losses annually. ${ }^{4}$ Reports in the USA show that $>350000$ people are treated for bites in emergency departments each year, a significant number of whom are hospitalised, require long-term drug treatment and undergo surgical procedures. ${ }^{56}$ Infections are the most common complications after a bite and the treatment of bite wounds is usually inappropriate and delayed; thus, the risk of acute infection and sequelae has increased. ${ }^{7}$ Timely post-exposure prophylaxis (PEP) treatment is necessary in order to reduce the risk of infections.

Dog bites account for tens of millions of injuries annually and the highest risk is among children. ${ }^{8}$ In China, many parents work outside and leave their children at home. Since the end of November 2016, the number of left-behind children under the age of 16 years was 9.02 million. ${ }^{9}$ Studies reveal that left-behind children suffered more mental health problems and psychological well-being neglect. ${ }^{10} 11$ Interaction with dogs could enhance people's physical and psychological health, promote a social support network between dog owners ${ }^{12}$ and create greater self-esteem, promote more exercise and reduce loneliness. ${ }^{13}$ Pet ownerships are 
most frequently observed in families with children, which may play an important role in animal injuries.

Given the unique social and cultural background of China, better understanding and identifying the factors associated with PEP treatment of dog and cat bites are important in left-behind children. Shenzhen (a well-developed city) and Shantou (a developing city) are two different-sized cities and their economies differ from each other. Up to now, no research has been conducted to investigate the characteristics and factors associated with PEP treatment in animal bites related injuries in the two cities. Our study, therefore, aims to investigate and explore the characteristics and factors associated with PEP treatment of dog and cat bites in left-behind children in two cities of China.

\section{METHODS}

\section{Study setting and its features}

Shenzhen and Shantou are two different-sized cities and their economies differ from each other. The two cities were chosen as study locations for the following reasons: on the one hand, their gross domestic products and populations vary evidently, which might play a significant impact on PEP treatment of dog and cat bites; on the other hand, Shenzhen, as one of the top four megacities and the first special economic zone in southern China, is a well-developed city and is adjacent to Hong Kong, with its population of 11.91 million; conversely, Shantou, as one of the seven special economic zones in eastern China, is a developing city with its population of 5.58 million. ${ }^{14}$ In addition, Shenzhen is an economically developed area, and the government in Shenzhen attaches great importance to education. What is more, in terms of owning a $\mathrm{dog}$, there are written rules on dog raising management made by Chinese government policies that are similar in both Shenzhen and Shantou cities. ${ }^{15}$ First, residents of both cities are required to register and have their dogs vaccinated against rabies by an authorised agency, otherwise they are fined and even their dogs will be confiscated. Second, if a dog hurts someone, the dog owner should immediately send the victim to a hospital for diagnosis and receiving PEP treatment, pay the medical expenses and bear the corresponding civil liability according to law. More information about the two cities is shown in table 1.

\section{Study design and data source}

In April 2015, a cross-sectional study was conducted on all dog and cat bite cases among left-behind children (aged 6-19 years) residing in two cities (Shenzhen and Shantou) of Guangdong province, southern China. A multistage random sampling method was used to ensure the reliability and representativeness of the data collection. First, 7 schools (including 3 primary schools, 2 junior high schools and 2 senior high schools) in Shenzhen and 10 schools (including 3 primary schools, 4 junior high schools and 3 senior high schools) in Shantou were selected randomly. Second, of all the selected schools, students in grades 1-11 were invited to fill in a self-designed questionnaire that included personal information (age, gender,

Table 1 Characteristics of the study population in a sample of 9380 in Shenzhen and Shantou cities, China and city statistic information

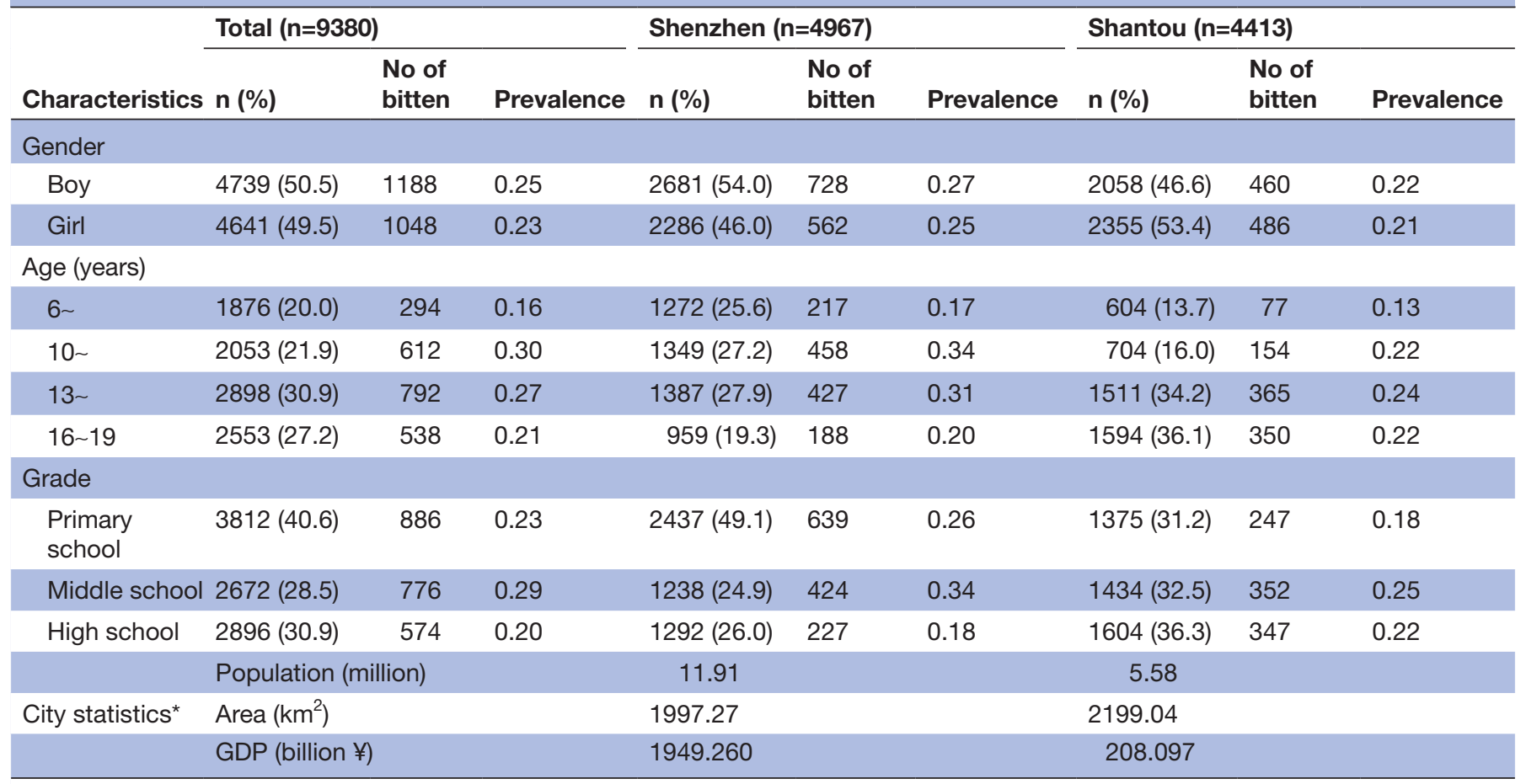

*2017 Statistical yearbook. ${ }^{14}$

GDP, gross domestic products. 
Table 2 Recommended PEP for rabies infection

\section{Category of exposure to suspect rabid animal}

\section{Post-exposure measures}

Category I-touching or feeding animals, licks on intact skin (ie, no None exposure)

Category II-nibbling of uncovered skin, minor scratches or abrasions without bleeding

Immediate vaccination and local treatment of the wound

Category III-single or multiple transdermal bites or scratches, licks Immediate vaccination and administration of rabies on broken skin; contamination of mucous membrane with saliva from immunoglobulin; local treatment of the wound licks, exposures to bats.

PEP, post-exposure prophylaxis.

personality, grade, parents' education, average monthly income and others) and animal injuries experiences (injured part, place where the injury happened, severity of wound, vaccination status of involved animal, PEP treatment and others). They completed their questionnaires with the help of trained investigators in the classroom. All questionnaires were collected in the classroom and were checked immediately to assure its accuracy and completeness. Before the launch of a formal investigation, our preliminary investigation showed a good reliability and correlation coefficient between 0.786 and $0.851 \quad(\mathrm{p}<0.01)$. Written informed consent forms were got from students' parents in advance.

\section{Definition}

Left-behind children were defined as those who stay in their hometowns while one or both parents work away from home for at least 6 months. ${ }^{16}$ In our study, the type of involved animals only meant dogs and cats. In addition, PEP was the abbreviation of post-exposure prophylaxis. For the purpose of our study, receiving timely PEP was defined as the initiation of prevention and treatment measures of category II and III exposure to suspect rabid animal $\leq 24$ hours after animal bites. ${ }^{17}$ The recommended PEP depends on the category of exposure to suspected or confirmed rabid animals (table 2). ${ }^{18}$

\section{Statistical analyses}

Data were analysed by SPSS V.19.0 software. Descriptive analysis was applied to describe the characteristics of the two cities. In addition, differences between age, gender, personality, grade, parents' education, average monthly income, city, ownership of involved animal, vaccination status of involved animal, severity of wound, injured body part, companionship, place where the injury happened and PEP treatment were also analysed. All variables in our study were categorical variables. $\chi^{2}$ test was used as a univariable analysis to test the associations of factors with PEP treatment of dog and cat bites in the two cities. Once the variables were identified, a binary logistic regression analyses, using forward stepwise regression with the criteria of $p<0.05$ for entry and $p<0.10$ for removal, was performed to control the potential confounding factors so as to assess which independent variables may explain the likelihood of a victim receiving PEP treatment. PEP treatment, a binary variable, was considered as the dependent variable in the binary logistic regression model. OR and $95 \%$ CI were used to evaluate the associations between the factors and PEP treatment. A two-tailed $\mathrm{p}<0.05$ was adopted to indicate statistical significance.

\section{Patient and public involvement}

No patients or public were involved in the recruitment to or conduct of the study. The results of this study were not disseminated to the study participants but have informed the management department of involved schools.

\section{RESULTS}

Demographic and injury characteristics of the study population, as well as the number of bitten children by animal in Shenzhen and Shantou, were shown in tables 1 and 3, respectively. The study population included 9380 participants from the two cities, of which 2236 left-behind children (1290 in Shenzhen and 946 in Shantou) aged 6-19 years were included in all analyses, with a history of animal bites. The sample contained 1188 boys $(53.1 \%)$ and 1048 $(46.9 \%)$ girls, and the boy to girl gender ratio was 1.13 in the injury population. The median age of victims was 16 in Shenzhen compared with 14 in Shantou. In Shenzhen, most injuries occurred in primary school $(49.5 \%, \mathrm{n}=639)$, while in Shantou middle school had the large proportions $(37.2 \%, \mathrm{n}=352)$.

The result of univariable analysis about PEP treatment of animal bites was presented in table 3 . There were significant differences in the PEP treatment among certain age groups, monthly income, city, vaccination status of involved animal, severity of wound, injury time, injured part, place, ownership and companionship. There were no significances in gender, personality and parents' education lever.

After using multivariate logistic regression analysis (shown in table 4), we found that injury time was a risk factor of receiving PEP treatment of animal bites among left-behind children. Among the victims, those bitten in holidays were less likely to receive PEP treatment (OR $0.512,95 \%$ CI 0.377 to 0.695 ) than those bitten in school days. Children who were with their family members tended to receive PEP treatment after an animal bite, 
Table 3 Univariable analysis about PEP treatment of anima bites among left-behind children $(n=2236)(Y=$ treatment, $\mathrm{N}=$ no treatment)

\begin{tabular}{lrrrr}
\hline & \multicolumn{2}{l}{ PEP treatment } & & \\
\cline { 2 - 3 } Variables & $\mathbf{Y}(\mathbf{n} / \%)$ & $\mathbf{N}(\mathbf{n} / \%)$ & $\chi^{2}$ & P value \\
\hline Gender & & & & \\
Boy & $182(15.8)$ & $969(84.2)$ & 0.012 & 0.913 \\
Girl & $160(16.0)$ & $841(84.0)$ & & \\
Age (years) & & & & \\
6 & $38(13.8)$ & $238(86.2)$ & 9.652 & 0.022 \\
10 & $91(15.3)$ & $504(84.7)$ & & \\
13 & $109(14.2)$ & $656(85.8)$ & & \\
16 19 & $104(20.2)$ & $412(79.8)$ & & \\
Personality & & & & \\
Introversion & $59(18.2)$ & $265(81.8)$ & 4.403 & 0.111 \\
Normal & $170(14.4)$ & $1013(85.6)$ & & \\
$\quad$ Extroversion & $103(17.4)$ & $488(82.6)$ & & \\
\hline
\end{tabular}

\begin{tabular}{lrrrr}
\hline Father's education level & & & \\
\hline $\begin{array}{l}\text { Primary school } \\
\text { or less }\end{array}$ & $51(16.9)$ & $250(83.1)$ & 4.006 & 0.261 \\
$\begin{array}{l}\text { Middle school } \\
\text { High school }\end{array}$ & $144(16.1)$ & $751(83.9)$ & \\
$\begin{array}{l}\text { University or } \\
\text { above }\end{array}$ & $34(17.4)$ & $481(82.6)$ & \\
\hline
\end{tabular}

$\begin{array}{lrrrr}\begin{array}{l}\text { Mother's education level } \\ \text { Primary school }\end{array} & 93(17.4) & 443(82.6) & 1.360 & 0.715 \\ \text { or less } & & & \\ \quad \text { Middle school } & 127(15.3) & 704(84.7) & \\ \quad \text { High school } & 72(15.8) & 385(84.2) & \\ \begin{array}{l}\text { University or } \\ \text { above }\end{array} & 32(14.6) & 187(85.4) & \end{array}$

\begin{tabular}{|c|c|c|c|c|}
\hline \multicolumn{5}{|l|}{ Monthly income* } \\
\hline Low & $233(17.7)$ & $1035(82.3)$ & 7.049 & 0.029 \\
\hline Average & $71(12.8)$ & $483(87.2)$ & & \\
\hline High & $34(15.1)$ & $191(84.9)$ & & \\
\hline \multicolumn{5}{|l|}{ City } \\
\hline Shenzhen & $164(13.2)$ & $1081(86.8)$ & 16.344 & $<0.001$ \\
\hline Shantou & $178(19.6)$ & $729(80.4)$ & & \\
\hline \multicolumn{5}{|c|}{ Vaccination status of involved animal } \\
\hline Yes & $78(12.0)$ & $570(88.0)$ & 12.987 & 0.002 \\
\hline No & $118(19.4)$ & $490(80.6)$ & & \\
\hline Unknown & $1421(16.5)$ & $721(83.5)$ & & \\
\hline \multicolumn{5}{|l|}{ Severity of wound } \\
\hline Skin unbroken & $210(17.9)$ & $962(82.1)$ & 43.034 & $<0.001$ \\
\hline Bleeding & $53(9.4)$ & $513(90.6)$ & & \\
\hline Laceration & $20(11.0)$ & $162(89.0)$ & & \\
\hline Other & $54(26.9)$ & $147(73.1)$ & & \\
\hline \multicolumn{5}{|l|}{ Injury time } \\
\hline School days & $87(22.5)$ & $299(77.5)$ & 15.333 & $<0.001$ \\
\hline Holidays & $239(14.4)$ & 1417 (85.6) & & \\
\hline Ownership & & & & \\
\hline
\end{tabular}

Continued

\begin{tabular}{|c|c|c|c|c|}
\hline \multirow[b]{2}{*}{ Variables } & \multicolumn{2}{|c|}{ PEP treatment } & \multirow[b]{2}{*}{$\chi^{2}$} & \multirow[b]{2}{*}{$P$ value } \\
\hline & $Y(n / \%)$ & $N(n / \%)$ & & \\
\hline Family's & $153(19.5)$ & $632(80.5)$ & 13.066 & 0.004 \\
\hline Other family's & $124(13.7)$ & 784 (86.3) & & \\
\hline Stray & 30 (12.5) & $210(87.5)$ & & \\
\hline Other & 33 (16.0) & $173(84.0)$ & & \\
\hline \multicolumn{5}{|l|}{ Injured part } \\
\hline Hand & 192 (20.3) & 753 (79.7) & 29.992 & $<0.001$ \\
\hline Lower limbs & 88 (11.5) & $679(88.5)$ & & \\
\hline Head/neck & $10(10.5)$ & 85 (89.5) & & \\
\hline Trunk & 35 (12.4) & 247 (8.6) & & \\
\hline \multicolumn{5}{|l|}{ Companionship } \\
\hline Alone & $190(19.8)$ & $770(80.2)$ & 21.191 & $<0.001$ \\
\hline Family & $91(14.4)$ & $541(85.6)$ & & \\
\hline Others & $60(11.1)$ & 481 (88.9) & & \\
\hline \multicolumn{5}{|l|}{ Place } \\
\hline Own home & $165(20.8)$ & 630 (79.2) & 24.523 & $<0.001$ \\
\hline Roadside & 75 (12.4) & $528(87.6)$ & & \\
\hline Public place & 27 (12.6) & 187 (87.4) & & \\
\hline Animal's home & $47(12.5)$ & $329(87.5)$ & & \\
\hline Other & 24 (16.8) & 119 (83.2) & & \\
\hline
\end{tabular}

Please note that there were different missing data in different variables but the ratio of missing values was $<20 \%$ of the whole participants.

*Monthly income: low means $<5000 ¥$, average means 5000 $10000 ¥$, high means $>10000 ¥$.

PEP, postexposure prophylaxis.

compared with those being alone (OR 1.418, 95\% CI 1.040 to 1.934). In addition, compared with those bitten at their own home, those bitten at roadside were inclined to receive PEP treatment (OR 1.842, 95\% CI 1.297 to 2.171). Further, among severity of wound group, compared with skin unbroken, bleeding (OR 1.789, 95\% CI 1.165 to 2.745 ), laceration (OR $3.834,95 \%$ CI 2.310 to 6.366 ) and others (OR 2.752, 95\% CI 1.436 to $5.276)$ were shown as treatment prompting or protecting factors. As for injured part, left-behind children tended to receive PEP treatment if they hurt their lower limbs (OR 1.777, 95\% CI 1.304 to 2.423) and trunks (OR 1.691, $95 \%$ CI 1.092 to 2.619 ) by a dog or a cat, compared with hurt their hands. If left-behind children were bitten by unvaccinated animals, they would be likely to receive PEP treatment (OR 1.745, 95\% CI 1.246 to 2.443 ).

\section{DISCUSSION}

To our knowledge, $299 \%$ of human rabies cases are resulted from dog bites and, once the symptoms of rabies emerge, the disease is almost inevitably fatal. ${ }^{19}$ Animal bites are fatal causes of morbidity and mortality around the world, but it can be prevented by timely and appropriate PEP treatment. ${ }^{20}$ It is needless to say that the quality 
Table 4 Multivariate logistic regression analyses of PEP treatment of animal bites among left-behind children

\begin{tabular}{|c|c|c|}
\hline Variables & OR (95\% Cl) & $P$ value \\
\hline \multicolumn{3}{|l|}{ Injured part } \\
\hline Hand & 1.000 & \\
\hline Lower limbs & 1.777 (1.304 to 2.423$)$ & $<0.001$ \\
\hline Head/neck & 2.045 (0.985 to 4.246$)$ & 0.055 \\
\hline Trunk & 1.691 (1.092 to 2.619$)$ & 0.019 \\
\hline \multicolumn{3}{|l|}{ Companionship } \\
\hline Alone & 1.000 & \\
\hline Family & 1.418 (1.040 to 1.934$)$ & 0.027 \\
\hline Others & 1.898 (1.328 to 2.716$)$ & $<0.001$ \\
\hline \multicolumn{3}{|l|}{ Place } \\
\hline Own home & 1.000 & \\
\hline Roadside & 1.842 (1.297 to 2.171$)$ & 0.001 \\
\hline Public place & 1.439 (0.868 to 2.386$)$ & 0.158 \\
\hline Animal's home & $1.221(0.829$ to 1.797$)$ & 0.313 \\
\hline Other & $1.716(0.936$ to 3.145$)$ & 0.081 \\
\hline
\end{tabular}

Injury time

\begin{tabular}{|c|c|c|}
\hline School days & 1.000 & \\
\hline Holidays & $0.512(0.377$ to 0.695$)$ & $<0.001$ \\
\hline \multicolumn{3}{|c|}{ Severity of wound } \\
\hline Skin unbroken & 1.000 & \\
\hline Bleeding & 1.789 (1.165 to 2.745$)$ & 0.008 \\
\hline Laceration & 3.834 (2.310 to 6.366$)$ & $<0.001$ \\
\hline Other & 2.752 (1.436 to 5.276$)$ & 0.002 \\
\hline
\end{tabular}

Vaccination status of

involved animal

\begin{tabular}{lll} 
Yes & 1.000 & \\
\hline No & $1.745(1.246$ to 2.443$)$ & 0.001 \\
\hline Unknown & $0.902(0.663$ to 1.228$)$ & 0.514 \\
\hline
\end{tabular}

Because the variables were not significant in the univariable analysis form or had a $p$ value of $>0.05$, they were not included in multivariate logistic regression form.

$\mathrm{OR}<1$ meant the variable is a risk factor of receiving PEP treatment, that was to say, left-behind children would be less likely to receive PEP treatment after exposure to an animal bite. PEP, post-exposure prophylaxis.

of the initial medical care received by the victims has a significant impact on the long-term function and quality of their lives.

Most studies conducted in different countries showed that most animal bites occurred in males ${ }^{21-24}$ which was in concordance with the results of the present study. That is to say, compared with girls, boys had a higher likelihood of being injured by animals, which could be explained by the fact that boys were more active, extroverted and adventurous than girls. Animal bite prevention should continue to target all children and their family, particularly in boys, and must also include parents to reduce the risk of bites for children. ${ }^{25}$
Several researches conducted in different countries revealed that the majority of animal bites, particularly when dogs were involved, were suffered by children. ${ }^{6326}$ More and more families keep dogs as pets. Pets were considered as having potential roles in children's social networks and were often ranked higher than certain kinds of human relationship, and they featured prominently as providers of comfort, esteem support and confidantes for a secret. ${ }^{27}$ In our study, compared with school days, if children suffered from animal bites during holidays, they were not inclined to receive PEP treatment. As we know, during school days, the teachers would take the students exposure to animal bites to emergency department or outpatient clinic to receive PEP treatment. However, when not at school, left-behind children, brought up by grandparents or having poor economic status, bad relationship and low frequency of communication with parents, were prone to encounter more loneliness. ${ }^{10}$ Thus, without parents' supervision and care, they might tend to interact and play with animals, which increased the chance of animal bites injury. Children are more vulnerable to animal bites for they often provoke animals without recognising the emotions or behavioural signals of animals. ${ }^{28} 29$ This indicates that teaching children how to appropriately interact with animals when they are alone would be a critical component of preventing this kind of animal bites. What is more, in another study, ${ }^{30}$ dogs owned by the victim were more than twice as likely to be responsible for bites. Understanding which place may be most likely to pose the greatest risk for animal bites allows children to take preventive actions before severe bite incidents with tragic outcomes occur. Particularly, left-behind children are unable to obtain adequate and timely care due to personal or financial reasons, which makes them be more vulnerable to psychological problems or physical injuries in their long-term personal development. ${ }^{31} 32$ Our study showed that left-behind children were likely to receive PEP when with their family members or others. All above, the most practical and direct way is that children should keep their guardian informed in the initial stage after a bite and be sent to receive timely and appropriate PEP treatment. Raising left-behind children's awareness of receiving PEP treatment after exposure to animal bites is extremely urgent.

Severity of wound was an influential factor associated with PEP treatment. The result of the present study was consistent with other studies. ${ }^{22}{ }^{24}$ As for injured part, our study showed that it was also a potential factor. Left-behind children would likely to receive PEP treatment when they got their lower limbs or trunk injured. This may possibly due to these body parts were severely injured. A bite can transmit unusual pathogens from the saliva into the wound. The risk of infection after bitten by animal is about $10 \%-20 \%$, and $30 \%-60 \%$ of the infections are of mixed aerobic-anaerobic origin. ${ }^{2}$ The size of wounds is critical because, particularly when it is $>3 \mathrm{~cm}$, the risk of infections significantly increases. ${ }^{33}$ Another study ${ }^{21}$ found $35.0 \%$ reduction in the risk of delay PEP treatment 
in the case of deep wounds. That was probably because participants who had deep wounds visited emergency department or outpatient clinic to seek for standard management and receive antirabies treatment as soon as possible. A bite that appears harmless on the surface may involve clinically significant tissue injury in the depths of the wound, thus, it is crucial to take proper PEP treatment in time.

The medical, psychological and socioeconomic consequences of rabies have an extensive impact on individuals, families and communities. Animal bite victims often underestimate the seriousness of smaller injuries. There is a potential rabies exposure from any scratch or bite wounded by an animal that may be infected through animal's saliva. In fact, animal bites are preventable injuries. Pre-exposure rabies prophylaxis is safe and immunogenic. ${ }^{34}$ The general management of bites is no difference from that usually recommended for wounds of any origin. ${ }^{7}$ For example, teaching children or their guardian to wash the site of bite vigorously with water and soap but the margins of puncture wounds should be excised and left open, whereas those of other wounds should be carefully excised and closed. Healthcare providers should be educated on the appropriate management of dog bites. Health authorities and policymakers should ensure rabies control within dog populations, ensure appropriate supplies of rabies vaccines for potential rabies exposure in people and develop data collection systems to further document the burden of this problem.

There are some limitations in our study. First, all collected information was based on self-reported questionnaires, therefore potential response bias may be present. Second, perhaps some students were not report their exposure to dogs or cats for fearing that they would be blamed or punished when their parents or teachers knew their real experiences. Consequently, we may underestimate the rate of dog or cat bites. Third, only two cities were as study settings in our study. Therefore, the results of the present research may not be generalised to represent the overall population of China. Despite these limitations, the current study demonstrated the characteristics and factors associated with PEP treatment of $\mathrm{dog}$ and cat bites among left-behind children in the cities of China. Initiating PEP treatment immediately after exposure to an animal bite is highly effective in preventing rabies. Certain measures should be taken to raise left-behind children's awareness of seeking care for PEP treatment such as going to emergency department or outpatient clinic for standard treatment after a bite.

Acknowledgements The authors thank all of the lovely children and their parents and teachers for their time and participation in the study, and thank our teachers and workmates for their help.

Contributors SY, YC, WY, FC and LL were responsible for conceptualisation of the study and formulate the research goals and aims. SY, YC and LL contributed to the literature search, study design, data collection, writing and critical revision. WY and FC contributed to data interpretation and critical revision. All authors have approved the final version of the article submitted and agree to be accountable for all aspects of the work.
Funding The authors have not declared a specific grant for this research from any funding agency in the public, commercial or not-for-profit sectors.

Competing interests None declared.

Patient consent for publication Obtained.

Ethics approval This study was approved by the Ethics Committee of the Shantou University Medical College (No SUMC-2015-41).

Provenance and peer review Not commissioned; externally peer reviewed.

Data sharing statement № additional data are available.

Open access This is an open access article distributed in accordance with the Creative Commons Attribution Non Commercial (CC BY-NC 4.0) license, which permits others to distribute, remix, adapt, build upon this work non-commercially, and license their derivative works on different terms, provided the original work is properly cited, appropriate credit is given, any changes made indicated, and the use is non-commercial. See: http://creativecommons.org/licenses/by-nc/4.0/.

\section{REFERENCES}

1. Norton C. Animal and human bites. Emerg Nurse 2008;16:26-9.

2. Rothe K, Tsokos M, Handrick W. Animal and Human Bite Wounds. Dtsch Arztebl Int 2015;11243:433-42.

3. Hampson K, Coudeville L, Lembo T, et al. Correction: Estimating the global burden of endemic canine rabies. PLoS Negl Trop Dis 2015;9:e0003786.

4. Hampson K, Coudeville L, Lembo T, et al. Estimating the global burden of endemic canine rabies. PLoS Negl Trop Dis 2015;9:e0003709.

5. Centers for Disease Control and Prevention (CDC). Nonfatal dog bite-related injuries treated in hospital emergency departmentsUnited States, 2001. MMWR Morb Mortal Wkly Rep 2003;52:605-10.

6. Benson LS, Edwards SL, Schiff AP, et al. Dog and cat bites to the hand: treatment and cost assessment. J Hand Surg Am 2006;31:468-73.

7. Esposito S, Picciolli I, Semino M, et al. Dog and cat bite-associated infections in children. Eur J Clin Microbiol Infect Dis 2013;32:971-6.

8. Animal bites. http://www.who.int/en/news-room/fact-sheets/detail/ animal-bites2018.

9. http://news.china.com.cn/txt/2017-10/10/content_41710367.htm [accessed 26 Feb 2018].

10. Jia Z, Tian W. Loneliness of left-behind children: a crosssectional survey in a sample of rural China. Child Care Health Dev 2010;36:812-7.

11. Zhao X, Chen J, Chen MC, et al. Left-behind children in rural China experience higher levels of anxiety and poorer living conditions. Acta Paediatr 2014;103:665-70.

12. Knight S, Edwards V. In the company of wolves: the physical, social, and psychological benefits of dog ownership. J Aging Health 2008;20:437-55.

13. McConnell AR, Brown CM, Shoda TM, et al. Friends with benefits: on the positive consequences of pet ownership. J Pers Soc Psychol 2011;101:1239-52.

14. Statistic Bureau of Guangdong Province. Statistical yearbook. Available online. 2017 http://www.gdstats.gov.cn/ (accessed 28 Feb 2018).

15. Chinese government legal information. 2018. http://www.chinalaw. gov.cn/ (accessed 1 Mar 2018).

16. Wu YL, Ding XX, Li YF, et al. Children in rural China enjoyed a significant increase in quality of life from 2009 to 2011. Acta Paediatr 2015;104:849-54.

17. Miao C. Prevention and treatment measures of class II and III exposure after animal bite. Chinese Community Doctors 2017;36:14-16.

18. http://www.who.int/rabies/about/home_treatment/en/ (accessed 10 Jun 2018).

19. Crowcroft NS, Thampi N. The prevention and management of rabies. BMJ 2015;350:g7827.

20. Franka R, Wu X, Jackson FR, et al. Rabies virus pathogenesis in relationship to intervention with inactivated and attenuated rabies vaccines. Vaccine 2009;27:7149-55.

21. Esmaeilzadeh F, Rajabi A, Vahedi S, et al. Epidemiology of animal bites and factors associated with delays in initiating post-exposure prophylaxis for rabies prevention among animal bite cases: A population-based study. J Prev Med Public Health 2017;50:210-6.

22. Khazaei S, Rezaeian S, Soheylizad M, et al. Factors associated with delay in post-exposure prophylaxis in bitten people. Med J Islam Repub Iran 2014;28:158. 
23. Gautret P, Le Roux S, Faucher B, et al. Epidemiology of urban dog-related injuries requiring rabies post-exposure prophylaxis in Marseille, France. Int J Infect Dis 2013;17:e164-e167.

24. Joseph J, N S, Khan AM, et al. Determinants of delay in initiating post-exposure prophylaxis for rabies prevention among animal bite cases: hospital based study. Vaccine 2013;32:74-7.

25. Morrongiello BA, Schwebel DC, Stewart J, et al. Examining parents' behaviors and supervision of their children in the presence of an unfamiliar dog: does The Blue Dog intervention improve parent practices? Accid Anal Prev 2013;54:108-13.

26. Lyu C, Jewell MP, Piron J, et al. Burden of bites by dogs and other animals in los angeles county, California, 2009-2011. Public Health Rep 2016;131:800-8.

27. McNicholas J, Collis GM. Children's representations of pets in their social networks. Child Care Health Dev 2001;27:279-94.

28. Bernardo LM, Gardner MJ, O'Connor J, et al. Dog bites in children treated in a pediatric emergency department. $J$ Soc Pediatr Nurs 2000;5:87-95.
29. Cornelissen JM, Hopster H. Dog bites in The Netherlands: a study of victims, injuries, circumstances and aggressors to support evaluation of breed specific legislation. Vet $J$ 2010;186:292-8.

30. Matthias J, Templin M, Jordan MM, et al. Cause, setting and ownership analysis of dog bites in Bay County, Florida from 2009 to 2010. Zoonoses Public Health 2015;62:38-43.

31. Guo J, Chen L, Wang X, et al. The relationship between Internet addiction and depression among migrant children and left-behind children in China. Cyberpsychol Behav Soc Netw 2012;15:585-90.

32. Gao Y, Li L, Chan EY, et al. Parental migration, self-efficacy and cigarette smoking among rural adolescents in south China. PLoS One 2013;8:e57569.

33. Jaindl M, Grünauer J, Platzer P, et al. The management of bite wounds in children-a retrospective analysis at a level I trauma centre. Injury 2012;43:2117-21.

34. Kessels JA, Recuenco S, Navarro-Vela AM, et al. Pre-exposure rabies prophylaxis: a systematic review. Bull World Health Organ 2017; $95: 210-9$ 